\title{
Immunosenescence Modulation by Vaccination
}

\author{
Janet E. McElhaney
}

\begin{abstract}
A decline in immune function is a hallmark of aging that leads to complicated illness from a variety of infectious diseases, cancer and other immune-mediated disorders, and may limit the ability to appropriately respond to vaccination. How vaccines might alter the senescent immune response and what are the immune correlates of protection will be addressed from the perspective of (1) stimulating a previously primed response as in the case of vaccines for seasonal influenza and herpes zoster, (2) priming the response to novel antigens such as pandemic influenza or West Nile virus, (3) vaccination against bacterial pathogens such as pneumococcus and pertussis, (4) vaccines against bacterial toxins such as tetanus and Clostridium difficile, and (5) vaccine approaches to mitigate effects of cytomegalovirus on immune senescence. New or improved vaccines developed over recent years demonstrate the considerable opportunity to improve current vaccines and develop new vaccines as a preventive approach to a variety of diseases in older adults. Strategies for selecting appropriate immunologic targets for new vaccine development and evaluating how vaccines may alter the senescent immune response in terms of potential benefits and risks in the preclinical and clinical trial phases of vaccine development will be discussed.
\end{abstract}

\section{Keywords \\ Vaccination $\bullet$ Correlates of protection $\bullet$ CD4 T cells $\bullet$ CD8 T cells $\bullet$ Antibodies $\bullet$ Cytokines • Granzyme B • Influenza - Herpes zoster • Pneumococcus • Cytomegalovirus}

\footnotetext{
J.E. McElhaney $(\bowtie)$

Health Sciences North Research Institute, 41 Ramsey Lake Road, Sudbury, ON, Canada

e-mail: jmcelhaney@hsnri.ca
} 


\section{Contents}

Immune Senescence: Stimulating a Previously Primed Response $\ldots \ldots \ldots \ldots \ldots \ldots \ldots \ldots \ldots, \quad 3$

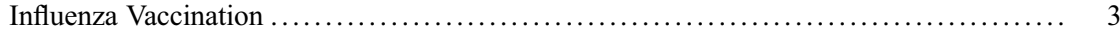

New Vaccines for Herpes Zoster ....................................... 10

Implications of Effective Vaccines Against Respiratory Syncytial Virus .............. 13

Immune Senescence: Stimulating a Naïve Response .............................. 15

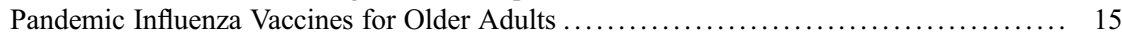

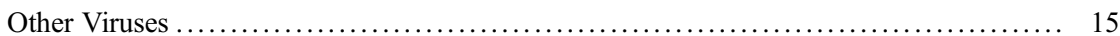

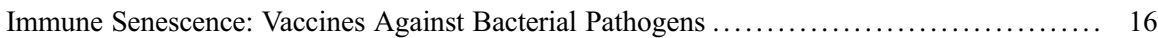

Pneumococcal Vaccination ................................................ 16

Immune Senescence: Altering Responses to Endogenous Proteins . . . . . . . . . . . . . . . 18

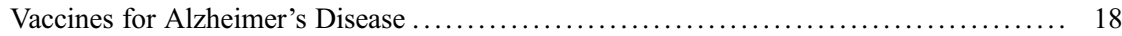

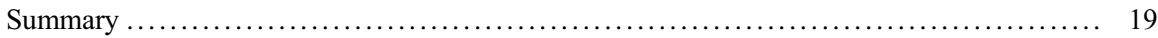

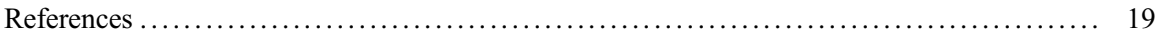

This chapter focuses on vaccine preventable diseases and the effect of vaccination on the senescent immune response to specific pathogens, observed in communitydwelling older adults and relevant experiments in animal models. It is important to distinguish these studies from those in older people in the nursing home setting who represent a minority of the population aged 65 years and older; multiple chronic diseases, disability, and frailty contributing to further loss of immune function may no longer be representative of the senescent phenotype. As a population, the majority of older adults experience "usual aging" where independence is maintained in the community but risk for functional decline during an acute illness increases with chronic disease burden and frailty. From a public health perspective, usual aging older adults are the largest segment of the population aged 65 years and older and should be the target population for new vaccine development; the goal is to compress morbidity to the extremes of life - "adding life to years."

A second focus of this chapter is to highlight the challenges in vaccine development for older adults and how vaccines may interact with the senescent immune response in ways that are not predictable using standard correlates of protection such as antibody titers to evaluate potential efficacy. The goal of vaccination in this population should be clinical protection against serious illness rather than sterilizing immunity; sterilizing immunity is predicted by the level of antibody titers needed to prevent infection as a surrogate of vaccine efficacy, whereas estimates of vaccine effectiveness and clinical protection requires an evaluation of both humoral and cellmediated immune responses to a vaccine or the relevant pathogen. In addition, new vaccines should be tested in usual aging older adults who experience common medical conditions and mental and psychosocial health issues, all of which may interact with vaccine responsiveness. While studies of healthy older adults with no underlying chronic diseases or disability will help us to understand the effect of aging on the immune response, translating this research to improve health outcomes in the 65 and older population requires the identification of "modifiable risk" in both age-related and age-associated changes in immune function. 


\section{Immune Senescence: Stimulating a Previously Primed Response}

\section{Influenza Vaccination}

\section{Influenza, a Vaccine Preventable Disease in Older Adults}

Influenza is foremost among all infectious diseases in terms of risk for serious complications and death in older adults and has been a cost-saving intervention in this population. At least 36,000 deaths and more than 100,000 hospitalizations from respiratory and cardiovascular complications of influenza occur annually in the United States (Thompson et al. 2003, 2004). In spite of only 40-60\% efficacy in older adults (Govaert et al. 1994), current influenza vaccination programs are costeffective in older people and even cost saving in developed countries due to the 30-40\% reduction in influenza-related hospitalizations (Nichol et al. 1994; Vu et al. 2002). Hospitalizations rates are dramatically increased in adults aged 65 years and older in years when influenza $\mathrm{A} / \mathrm{H} 3 \mathrm{~N} 2$ is the predominant circulation strain, relative to the rates observed when $\mathrm{H} 1 \mathrm{~N} 1 \mathrm{pdm} 09$ virus has been the predominant circulating strain. The fact that seasonal influenza vaccines also prevent complications of influenza (pneumonia, heart attacks, strokes, and exacerbations of congestive heart failure) provides an even greater incentive to increase the use of existing vaccines and develop new vaccines that are targeted to improve vaccine efficacy (DiazGranados et al. 2014). However, the immune mechanisms which underlie the increased risk for complicated illness, and the recent decline in seasonal vaccine effectiveness against A/H3N2 strains (Belongia et al. 2016), are poorly understood.

\section{Influenza Virus Stimulates both Humoral and Cell-Mediated Immunity}

The effect of influenza vaccination on the senescent immune response is best understood from the perspective of the adaptive immune response to influenza and how this may be altered through vaccination. Influenza vaccine is the most studied vaccine in older adults and well understood in terms of the potential immunologic determinants of clinical protection in this population. Thus, the response to this virus in the context of age-related changes in the adaptive immune system will be discussed in significant detail as an example of what we might anticipate in terms of other potentially vaccine-preventable diseases in older people.

Influenza virus stimulates an antiviral response in bone-marrow-derived lymphocytes (B-cells), monocytes, and thymus-derived lymphocytes (T-cells) resulting in humoral and cell-mediated immunity, respectively. However, the effectiveness of this stimulus depends on the presentation of viral peptides to the $\mathrm{T}$ lymphocytes. There are two main cell types within the $\mathrm{T}$ lymphocyte population, helper T cells and cytotoxic $\mathrm{T}$ cells. Helper T cells are classically within the CD4 T cell subset and are further subtyped (according to the cytokines they produce) as Thelper type 1 (Th1), $\mathrm{T}$ helper type 2 (Th2), $\mathrm{T}$ follicular helper (Tfh), $\mathrm{T}$ regulatory (Treg), and $\mathrm{T}$ helper type 17 (Th17) cells. The response to influenza virus in adult populations is the result of restimulation of a previously primed response through exposure to natural infection or prior vaccination. Virus-activated T-cells, through a variety of cytokine mediators, stimulate B-cells to differentiate and produce antibodies that are specific 
for the strains of virus contained in the vaccine (Virelizier et al. 1974). These specific antibodies bind to the surface glycoproteins (hemagglutinin [HA] and neuraminidase [NA]), to neutralize the viral particle. The peptide sequences on the outer surfaces of HA and NA, which are the antibody-binding sites, change as a result of high mutation rates in the influenza virus and selective pressure by the immune system against the native virus, a phenomenon known as antigenic drift. These changes in the HA identify a new circulating strain of influenza virus requiring annual updates in the influenza vaccine strains to ensure that antibody-mediated immunity is stimulated to the relevant predicted strains of the H3N2 and H1N1 subtypes of influenza A and influenza B.

Hemagglutination inhibition assays are the current industry standard for measuring antibody responses to influenza vaccination as a proxy for vaccine efficacy. There is a significant literature reporting a decline in antibody responses to influenza vaccination with aging (Goodwin et al. 2005). However, recent studies suggest that this observed decline may not be related to aging but instead to the effect of prior exposure to influenza (Reber et al. 2015) and repeated annual vaccination (Mosterin Hopping et al. 2016), and the phenomenon of original antigenic sin, more recently identified as antigenic seniority (Kucharski et al. 2015). Even though the B cell response to influenza vaccination is maintained in older adults, the antibody response is not; this appears to be impaired differentiation of B cells to antibodyproducing plasma cells due to a decline in the activity of activation-induced cytidine deaminase (AID) and the transcription factor E47. These results highlight the fact the changes in the immune response with aging cannot be attributed to immune senescence alone and are further complicated when one considers the health status of study participants, their vaccination status, or the setting in which they were living. Clearly, factors that contribute to increasing frailty are expected to cause a further decline in immune responsiveness. These results suggest that additional mechanisms beyond antibody responses are involved in the loss of protection particularly against A/H3N2 strains with aging. Furthermore, even though the antibody response to vaccination might be predicted to decrease with repeated vaccination in older adults, annual repeated vaccination, in fact, improves protection against influenza in this population (Keitel et al. 1988; Ahmed et al. 1995; Voordouw et al. 2004) while annual repeated vaccination in children and adults has been associated with a loss of protection (McLean et al. 2014). Even so, the ability to mount a fourfold increase in antibody titers in response to influenza vaccination has been associated with a twofold reduction in influenza disease (Benoit et al. 2015). However, large influenza vaccine trials have not been statistically powered to determine if this protection, consistent with sterilizing immunity (antibody neutralization of the virus to prevent infection), translates to a reduced risk of hospitalization; thus, correlates of clinical protection against $\mathrm{A} / \mathrm{H} 3 \mathrm{~N} 2$ disease (cell-mediated process to clear virus from the lungs) may be required. Vaccine-mediated protection may also be related to the duration of the antibody response to influenza vaccination, but a previous review of the literature found no difference between young and older adults in the rate of decay of antibody titers during the influenza season (Skowronski et al. 2008). 
There has been a paradigm shift in understanding the limitations of antibody titers as a sole measure of influenza efficacy (Effros 2007). As a correlate of protection against influenza, our studies have shown that serum antibody titers do not distinguish between older adults who will go on to develop A/H3N2 influenza illness from those who do not, and may fail to predict vaccine failure (McElhaney et al. 2006, 2009; Shahid et al. 2010). Although antibodies are an important defense mechanism, both humoral and cell-mediated immunities are important for clinical protection in older adults (Murasko et al. 2002). A greater understanding of how T cell-mediated immunity contributes to increased protection against influenza is needed in the development of new influenza vaccines (reviewed in McElhaney et al. (2016)). Thus, the evaluation of the antibody response in clinical trials of new vaccines as a means to progress through the clinical trial phases to approve a new vaccine may fail to predict enhanced vaccine efficacy, particularly when efficacy is measured as a single endpoint of protection against all three vaccine strains (McElhaney et al. 2013). In this case, vaccine trials are more likely to give a true picture of enhanced efficacy when $\mathrm{A} / \mathrm{H} 3 \mathrm{~N} 2$ is the predominant circulating strain (DiazGranados et al. 2014).

\section{T-Cell Responses to Influenza Are Conserved Across Different Strains}

In contrast to B-cells that mount a subtype and strain-specific response, the antigenic determinants of the T-cell response are more conserved across the different strains of influenza. Thus, T-cell recognition and the response to influenza do not degrade with antigenic drift (Effros et al. 1977; Butchko et al. 1978; Russell and Liew 1979). Internal peptide sequences of hemagglutinin and neuraminidase are similar within the subtypes of influenza A (e.g., A/H3N2 vs. A/H1N1). Internal viral proteins (matrix and nucleoproteins) are conserved within the types of influenza (e.g., influenza A vs. B) (Mitchell and Callard 1983). Thus, peptides derived from surface glycoproteins and internal viral proteins stimulate helper T-cell and CTL responses that are cross-reactive within the strains of influenza A or influenza B. In other words, antibody responses are relatively strain-specific, while $\mathrm{T}$ cell responses are cross-reactive across strains within influenza A or B, and have been immunologic targets for the development of universal influenza vaccines.

Previous studies have shown that exposure of the entire respiratory tract to live influenza virus is the most effective method of inducing cross-reactive $\mathrm{T}$ cell responses to influenza virus infections (Nguyen et al. 1999). A direct comparison between different routes of infection showed that protection correlated with the size of the virus-specific CTL (CD8+) response in the lungs and associated lymphoid organs. Although self-renewing populations of virus-specific CD8 T cells are maintained in the lymphoid organs for many years after influenza and other respiratory virus infections, protective cellular immunity is short-lived and disappears within about 6 months (Nguyen et al. 1999). However, this T cell memory response to the internal proteins of the influenza virus, matrix (M1) and nucleoprotein (NP), can be recalled during infection and, in the absence of protective antibody titers, $\mathrm{CD} 4+$ and $\mathrm{CD} 8+\mathrm{T}$ cells, respectively, correlate with protection against $\mathrm{A} / \mathrm{H} 3 \mathrm{~N} 2$ (Wilkinson et al. 2012) and pdmH1N1 (Sridhar et al. 2013) in young adults. In older 
adults, the CTL response to split-virus influenza vaccines in older adults is enhanced when the vaccine has been exposed to influenza through natural infection in the previous influenza season (McElhaney et al. 2009).

\section{Effective Stimulation of Helper T Cells and CTL}

Virus is taken up and processed by antigen-presenting cells such as macrophages and dendritic cells, and the resulting peptides are presented with the major histocompatibility complex to activate T-cells. Helper T-cells $\left(T_{h}\right)$ recognize antigens presented by the major histocompatibility complex Class II (MHC II); MHC II is expressed almost exclusively on antigen-presenting cells, B-cells and T-cells (Hackett and Eisenlohr 1990). In contrast, CD ${ }^{+}$CTLs recognize viral peptides in combination with MHC I; MHC I is expressed on most cells in the body (Ennis et al. 1981). Structural viral proteins and both live and inactivated viruses are phagocytozed by macrophages and dendritic cells. The virus is processed within the antigenpresenting cell and presented in combination with MHC II to helper T-cells (Demotz et al. 1990). In contrast, viral peptides presented in combination with MHC I are generally the products of viral replication within the antigen-presenting cell, although antigen cross-presentation in dendritic cells is recognized as an important contribution in response to influenza vaccination (discussed below). Thus, the form of the viral antigen and the interaction with a specific MHC and its cellular location independently determine $T_{h}$ and CTL responses to vaccination (Hackett et al. 1991; Lamb et al. 1991).

Antigen cross-presentation is the process by which antigens including killed virus or viral proteins are taken up by the dendritic cells, undergo proteasomal degradation, and are processed for presentation on MHC I. Because inactive virus (contained in current parenteral influenza vaccines) is effectively presented on MHC II and not MHC I, helper T cells and B-cells are stimulated to produce good antibody responses, but only weak CTL responses are seen in adults. This CTL response is not observed in influenza-naïve individuals, and results from restimulation of a previously primed response to influenza through natural infection (Hackett et al. 1991; Lamb et al. 1991; Hosaka et al. 1988). This is the presumed mechanism by which inactivated viruses including split-virus influenza vaccines can stimulate CTLs (Askonas et al. 1982). The relevance of antigen cross-presentation to new vaccine development is that toll-like receptor (TLR) ligands (Plowden et al. 2004; Behzad et al. 2012), virosomes (Huckriede et al. 2005), virus-like particles (Bright et al. 2007), and potentially adjuvants (McElhaney et al. 2013; Puig-Barbera et al. 2004) can be used to activate antigen-presenting cells and enhance expression of MHC I-viral peptide complexes and improve the poor CTL responses elicited by the current killed virus vaccines. Boosting T cell responses is an important priority for vaccine development, in general, due to broader protection against serologically distinct strains of virus (Ray et al. 2004). Because immunosenescence alters several aspects of cell-mediated immune function, vaccine design can include independent strategies for effectively stimulating helper T cell and CTL responses. 


\section{Effect of T Helper Cell Function on the Response to Influenza}

The helper $T$ cell $\left(T_{h}\right)$-mediated immune response to influenza virus plays a key role in the generation of both humoral and CTL responses to influenza vaccination. $T_{h} 1$, $\mathrm{T}_{\mathrm{h}} 2$, Tregulatory (Treg), $\mathrm{T}$ follicular (Tfh), and $\mathrm{T}_{\mathrm{h}} 17$ all contribute to the immune response through interactions with $\mathrm{T}$ and $\mathrm{B}$ cells in the lymph nodes or bone marrow. These $T_{h}$ subsets are defined by their cytokine products and/or their location within lymphoid tissues. The $\mathrm{T}_{\mathrm{h}} 1$ cytokine, interferon- $\gamma($ IFN- $\gamma$ ), provides help along with IL-2 in the development of both B cell and CD8 CTL responses to influenza, and is down-regulated by the production of IL-10 from Treg (Gardner and Murasko 2002). $\mathrm{T}_{\mathrm{h}} 2$ also provide help to B cells but not CD8 CTL. The IFN- $\gamma$ :IL-10 ratio declines with age (Skowronski et al. 2011) and is inversely correlated with risk for influenza illness in older adults (McElhaney et al. 2006), suggesting that a shift toward a Th1 response to influenza vaccination is important for protection in older adults.

\section{The Role of Inflammatory Cytokines in Response to Influenza}

"Inflammaging," the overproduction of inflammatory cytokines in older people, is associated with an increased risk of age-related frailty, morbidity, and disability, while the anti-inflammatory response involving IL-10 and other mediators that could potentially weaken resistance to infection contributes to healthy aging (Franceschi et al. 2007). This is in contrast to the known inflammatory responses to viral infections that trigger a variety of pathways involved in host defense. It has been shown in aged mice and humans that the addition of inflammatory cytokines (IL-1, IL-6, and TNF- $\alpha$ ) or the combination of IL-2 and IL-6 can reverse age-related defects in $\mathrm{T}_{\mathrm{h}} 1$ cytokine production, proliferation, and function (Haynes et al. 2004). Our recent study has shown that these combined effects of IL-2 and IL-6 can restore influenza-specific CD8 CTL function in older adults to that observed in young adults in both mice and humans (Zhou et al. 2016), and suggests a mechanism that can be targeted for developing more protective vaccines.

\section{Potential CTL-Associated Correlates of Protection Against Influenza in Older Adults}

Human studies have shown that CTL activity is important for recovery from influenza infection even in the absence of protective antibodies to the infecting virus strain (McMichael et al. 1983a). CTLs combat influenza viral infections by recognizing and destroying virus-infected host cells that become the factories for viral replication. Infected cells expressing on their surfaces the MHC I-viral peptide complex are recognized by and activate virus-specific CTL (Ennis et al. 1981). CTL activation leads to lysis of virus-infected cells by perforin- or granule-mediated killing (Pasternack and Eisen 1985; Bleackley et al. 1988; Jenne and Tschopp 1988), and is particularly important for the control of respiratory viral infections (Doherty et al. 1997).

Although self-renewing populations of virus-specific $\mathrm{T}$ cells are maintained for many years after influenza infection, protective cellular immunity is short-lived and disappears within 6 months (Nguyen et al. 1999; Ray et al. 2004; McMichael 
et al. 1983b). Even though current inactivated influenza vaccines stimulate a CTL response in older and even chronically ill older adults (Gorse and Belshe 1990), this response and degree of cross-reactivity is diminished compared to young adults (Powers 1993; Mbawuike et al. 1993; McElhaney 2005) and is not as robust as the response to vaccination following natural infection (McElhaney et al. 2009; Shahid et al. 2010).

Virus-specific killing is mediated by granzymes contained in granules within CTL. Granules migrate to the "immune synapse" between the activated CTL and the virus-infected target cell, are transported across the cell membrane into the cytoplasm of the target cell, and are involved in an enzymatic cascade that leads to apoptotic cell death (Darmon et al. 1995). Granzyme B (GrB) is a key element of the T-cell response to influenza in the lung (Johnson et al. 2003; Lawrence et al. 2005; Jenkins et al. 2007). An assay of GrB activity in lysates of influenza virus-stimulated PBMC correlates with cytolytic activity(Ewen et al. 2003), and low ex vivo levels of GrB predict increased risk for influenza illness in older adults (McElhaney et al. 2006, 2009; Shahid et al. 2010). Other ex vivo studies have shown no difference in influenza-specific CTL frequencies in older compared to young adults (Boon et al. 2002) and susceptibility in older adults may be due to decreased cytolytic activity (and the amount of GrB produced) on a per cell basis (Ouyang et al. 2003).

\section{Interaction of Antibody and Cell-Mediated Immune Response to Influenza Vaccination}

Inactivated influenza virus vaccines effectively stimulate $T$ helper cells, but in older adults, dysregulated cytokine production leads to a decline in the IFN $\gamma: \mathrm{IL}-10$ ratio in response to live virus challenge, and defects in the $\mathrm{B}$ cell response to vaccination (reviewed in Frasca and Blomberg (2014)) contribute to increased susceptibility to infection in this age group. A weakened CTL response to influenza that is poorly stimulated by inactivated vaccines contributes to the observed increased risk of serious complications. Recent developments including a high-dose influenza vaccine containing four times the amount of antigen in the standard dose vaccine has demonstrated a $24 \%$ improvement in efficacy against influenza illness and enhanced protection against hospitalizations for pneumonia during the influenza season. Liveattenuated intranasal vaccines were developed to provide more effective stimulation of CTL. However, these vaccines have shown minimal additional benefit in older adults probably due to neutralization of the vaccine virus by antibodies in the nasal mucosa (Gorse et al. 2003). Current efforts are focused on the use of adjuvants to improve vaccine-mediated protection.

\section{The Effect of Cytomegalovirus on Immune Function and Responses to Vaccination}

With aging and the multiple immune responses that have been stimulated throughout one's lifetime, there is a gradual shift from predominantly naïve T-cells to increasing proportions of memory T-cells. Thymic involution and the loss of naïve T-cells with aging may thus exhaust the capacity to respond to new antigens. An age-related decline in IL-7 levels that support thymic rejuvenation corresponds to failure to 
maintain or expand the effector memory helper T-cell response to influenza (Kang et al. 2004). More recently, this age-related change in the response to influenza has been associated with persistent cytomegalovirus (CMV) infection and the accumulation of late-differentiated $\mathrm{T}$ cells with a reversal in the normal CD4:CD8 T cell ratio, which declines to less than one. In CMV seropositive compared to seronegative older adults, there is a decline in the CD4 $\mathrm{T}$ cell response to influenza peptides derived from the influenza internal proteins, matrix (M), and nucleoprotein (NP), which is not seen in young adults (Derhovanessian et al. 2013). Further, this effect of CMV appears to be a major driver of the shift of the naive $T$ cell pool to the central and effector memory subsets (reviewed in Pawelec et al. (2005)). This effect is more pronounced in CD8 T cells and yet there is no difference in their response to M- and NP-derived peptides in seropositive versus seronegative older adults (Derhovanessian et al. 2014). These results suggest that additional mechanisms underlie age-related changes in CD8 T cells.

Poor survival is predicted by this inversion of the CD4:CD8 $\mathrm{T}$ cell ratio (Franceschi et al. 1995; Ferguson et al. 1995), yet these cells in both seropositive and seronegative older show enhanced inflammatory responses to polyclonal stimulation (Wikby et al. 2006). The phenomenon of replicative senescence has been associated with these changes and relates to the finite number of doublings (25-30 cycles) after which cell cycle arrest occurs (Effros 1997). In CTLs, growth arrest associated with replicative senescence also shows increased production of several pro-inflammatory cytokines, resistance to apoptosis (Effros et al. 2003), and loss of the costimulatory molecule, CD28, required for optimal stimulation of CTLs (Effros et al. 1994; Engwerda et al. 1994). CTL that do not express CD28 (CD28CTL) have little or no cytolytic activity (Effros 2003) and an increased proportion of CD28-CTLs is associated with a decline in antibody responses to influenza vaccination (Goronzy et al. 2001; Saurwein-Teissl et al. 2002) and a reduction in influenza-specific memory CTL (Xie and McElhaney 2007). These changes have been associated with chronic CMV infection driving the T-cell response to terminal differentiation and expressing this senescent phenotype (Vasto et al. 2007; Vescovini et al. 2007). However, it remains uncertain the extent to which this change may affect the $T_{h}$ and CTL responses to influenza and influenza vaccination.

\section{Summary}

Influenza is a serious illness in older adults and largely accounts for rising hospitalization and death rates from acute cardiac and respiratory illnesses in older people despite widespread influenza vaccination programs. While current vaccines are costsaving and new more efficacious vaccines have recently been approved, a margin for further improvement still remains. Recent studies suggest that there is a significant opportunity to exploit the reserve capacity of T-cells to respond to influenza antigens through enhanced antigen presentation, regulation of cytokine responses, and the addition of adjuvants. Targeting identified immunologic mediators that modulate influenza risk in older people, and screening candidate vaccines for clinical trials using appropriate correlates of protection in this population, is critical to development of more effective influenza vaccines for an aging population. Since the early 
phases of vaccine development often rely on antibody titers as a surrogate of protection, this measure may fail to detect a more robust T-cell response and thus, a more effective vaccine for the 65 and older population.

\section{New Vaccines for Herpes Zoster}

\section{Risk for Herpes Zoster and Aging}

Herpes zoster (or Shingles) is a painful blistering rash resulting from the reactivation of latent Varicella-zoster virus (VZV), the agent that causes chickenpox. Prior to routine vaccination for VZV, approximately $90 \%$ of people in the USA were infected with this virus and the chance of developing shingles during one's lifetime was $30 \%$ (Oxman and Levin 2008). The risk of developing shingles dramatically increases with age.

Older persons bear the greatest burden of illness related to zoster (also called shingles), the clinical condition that results from reactivation of latent Varicellazoster virus (VZV) within the dorsal root ganglia. Each year between 600,000 and 1 million Americans develop shingles and the risk dramatically increases with age $50 \%$ of persons over age 85 will suffer from the disabling complication of zoster, post-herpetic neuralgia (PHN). Despite extensive epidemiologic studies of risk, the immunologic determinants for reactivating this exclusively human herpesvirus are poorly understood, as there are limited animal models for mechanistic studies. T cellmediated immunity is essential for recovery from herpes zoster due to significant cell tropism of this virus. Varicella infection and "silent" reactivation of zoster appear to restimulate VZV-specific cellular immunity in adulthood but after age 50, this boost to the immune system becomes less effective, and thus the dramatic increase in the rates of zoster and PHN with aging.

\section{Shingles Is an Important and Disabling Disease in Older Adults}

VZV presents as chickenpox in childhood and becomes a latent infection in the dorsal root ganglion of the spinal cord. The increased risk of shingles with age has been well documented with an annual incidence of 14/1000 in those aged 75 years and older and an astonishing prevalence of up to $50 \%$ of those over age 85 years (Hope-Simpson 1965; Schmader 2001; Brisson et al. 2001). Reactivation causes a painful dermatomal rash called shingles that is often followed by PHN, a chronic pain syndrome defined as pain lasting for $>90$ days following zoster and associated with significant disability in older people. The incidence of PHN is almost negligible before age 50 , but at least $50 \%$ of patients older than 60 years and almost $75 \%$ beyond age 70 become affected following an attack of shingles. Health-related quality of life is significantly impacted by zoster with $>90 \%$ of over 65 year olds reporting pain with a median duration of 1 month (Drolet et al. 2010). The functional consequences of pain are significantly diminished with the resolution of zoster, but in the context of PHN, the pain and impact on daily function often continues for more than 6 months (Drolet et al. 2010). This contrasts with shingles in children where the rash generally follows a mild case of chicken pox and is of little clinical 
significance (Feder and Hoss 2004). Antiviral therapy is available but older people often do not present within the 48-72 $\mathrm{h}$ window of onset of the rash necessary for initiation of effective treatment. In addition, $20 \%$ of older people who receive therapy within the therapeutic window still experience pain 6 months after the onset of the rash (Cunningham and Dworkin 2000). Particularly given the number of people who do not seek or receive timely and effective treatment of shingles, the prevalence of disability and poor quality of life related to $\mathrm{PHN}$ is a major public health concern.

There is a significant literature on the impact of shingles on the quality of life in older people and on various therapeutic strategies for the management of PHN, the review of which is beyond the scope of this chapter, which focuses on prevention through vaccination. However, the importance of perceived quality of life and psychological conditions that have been identified from epidemiologic studies as risk factors for the development of shingles are relevant due to their potential impact on immune function. A review of these studies suggests that in addition to age, poor self-perceived health, psychological stress, and/or lack of social support and mechanical trauma may lead to loss of cell-mediated immunity to VZV and increased risk of shingles (Thomas and Hall 2004).

\section{The Link Between Risk for Shingles and Immunosenescence}

Because VZV is exclusively a human herpes virus (Cohrs et al. 2004), there are limited animal models that study the immunological mechanisms of VZV infection and reactivation (Baiker et al. 2004). However, much is known about the virology of VZV infection from studies of the live-attenuated Oka vaccine strain of VZV showing rapid evolution of the virus within the first 13 days of infection with no further replication of the virus once latency is established (Weinert et al. 2015). From the limited studies to date, it appears that with the resolution of chickenpox, VZV-specific CTL access the dorsal root ganglion where VZV lives, to keep viral replication in check (Baiker et al. 2004; Arvin et al. 1996). At some point, reactivation of latent VZV is associated with marked inflammation of the dorsal root ganglion leading to nerve cell damage and the pain associated with PHN often precedes the onset of the dermatomal rash. The latent virus escapes to replicate in nerves and skin to cause a very painful condition that continues even after the rash resolves and appears to be related to both central and peripheral nerve damage. Although there is a general decline in circulating VZV-specific $\mathrm{CD}^{+} \mathrm{T}$ cells with aging, these IFN- $\gamma$-secreting $\mathrm{T}$ cells demonstrate a robust response at the site of the shingles rash, with similar numbers and function to that seen in young adults. However, regulatory $\mathrm{T}$ cells (Foxp $3^{+} \mathrm{CD}^{+} \mathrm{T}$ cells) also accumulate at the site of infection in older adults and may inhibit the activity of otherwise functionally competent VZV-specific T cells (Vukmanovic-Stejic et al. 2013; Vukmanovic-Stejic et al. 2015). Although there are no identified immunologic correlates of protection against zoster reactivation, $\mathrm{VZV}$-specific $\mathrm{CD} 4+$ and $\mathrm{CD} 8+\mathrm{T}$ cells are believed to play a central role in latency and reactivation of the virus within the dorsal root ganglion (Arvin 2008; Steain et al. 2014; Gowrishankar et al. 2010). These results highlight the importance of designing vaccines to stimulate cell-mediated immunity 
to prevent reactivation of VZV and protect against zoster and PHN, rather than the usual focus on antibody responses to prevent infection.

\section{The Development of Zoster Vaccines for Older Adults}

A large randomized double-blind placebo-controlled of a shingles vaccine enrolling over 38,000 subjects showed in the vaccinated compared to the placebo group, a $61.1 \%$ reduction in burden of illness, a $51.3 \%$ reduction in shingles cases, and $66.5 \%$ reduction in those shingles cases complicated by post-herpetic neuralgia (Oxman et al. 2005). Furthermore, there was a reduction in the overall burden of illness in vaccinated subjects showing statistical significance for the primary end-point in the trial. The vaccine strain of VZV is a previously attenuated live virus (Oka strain) that is predicted to stimulate humoral, $\mathrm{T}_{\mathrm{h}}$, and CTL responses. Importantly for this disease, antibody titers do not predict protection from reactivating the virus to cause shingles. The postulated mechanism of protection is stimulation of the VZV-specific T-cell response to vaccination and measured by the IFN- $\gamma$ enzymelinked spot (ELISpot assay) (Levin et al. 2003; Smith et al. 2003). More recent studies have confirmed that the live attenuated zoster vaccine boosts both VZV-specific CD4 ${ }^{+}$and $\mathrm{CD}^{+}{ }^{+}$T cells (Sei et al. 2015), which appear to be important in preventing zoster reactivation and peripheral control of the infection in the nerves and skin. It is also important to highlight that this live attenuated vaccine Oka zoster strain was not identified in any of the VZV isolates from the skin of shingles cases in the vaccine trial, and thus can be safely and effectively used to stimulate the senescent immune response.

More recently, a recombinant subunit vaccine (HZ/su) containing VZV glycoprotein $\mathrm{E}$ and the AS01B adjuvant system (containing monophosphoryl lipid A (MPL) and QS21) has been developed and includes a two-dose regimen administered 2 months apart. A randomized placebo-controlled trial enrolled over 15,000 adults $\geq 50$ years old and demonstrated an estimate of overall vaccine efficacy of 97\% against herpes zoster over approximately 3 years of follow-up with no significant age-related decline in vaccine efficacy. Although reactions to the vaccine that affected performance of daily living activities (Grade 3) were significantly higher in vaccine recipients (17\%) compared to placebo recipients (3.2), there were no differences in the number of participants that went on to receive a second dose of vaccine or placebo in the study and no significant differences between the two groups in serious adverse events or potential immune-mediated diseases or deaths in the trial. Further, because there is no live virus in the vaccine, there is no concern about VZV infection of immunocompromised individuals. A parallel trial in adults $\geq 70$ years old using the same study protocol was designed to address vaccine efficacy for the prevention of post-herpetic neuralgia (Cunningham et al. 2016).

The mechanism of protection related to the HZ/su vaccine appears to be mediated by the stimulation of $\mathrm{CD}^{+} \mathrm{T}$ cells specific for the glycoprotein $\mathrm{E}$ subunit of VZV. Glycoprotein E promotes cell-to-cell interactions while other viral proteins promote cell fusion in the pathogenesis of the virus. The enhanced adaptive immune response 
to the glycoprotein E is dependent on AS01-mediated activation of dendritic cells and increased antigen presentation to the $\mathrm{CD}^{+} \mathrm{T}$ cells (Didierlaurent et al. 2014). However, there were too few zoster cases in this study to evaluate this CD4+ T cell response as a correlate of protection and further studies are needed to determine how the immune response to glycoprotein $\mathrm{E}$ offers protection against herpes zoster with no age-related decline in vaccine efficacy.

\section{Summary}

Shingles is a major debilitating disease in the older adult population. Both age-related and age-associated changes in the cell-mediated immune response to VZV are clearly associated with increased risk of reactivating the virus to cause shingles and persist as post-herpetic neuralgia. The fact that antiviral therapy has limited effectiveness in the treatment of zoster in older adults points to the need for strategies to prevent the disease and its disabling complications. However, the development of a vaccine against herpes zoster depended on a very large clinical trial to determine vaccine efficacy based on clinical outcomes. In the absence of reliable immunologic markers of vaccine efficacy, there was significant risk that the vaccine would fail to show an improvement. If the vaccine had failed in this trial, there may have been limited interest from industry in moving forward with alternate plans to develop an improved vaccine. This again points to the need for more reliable surrogates of vaccine efficacy to test new vaccines in the early phases of clinical development to select vaccines most likely to improve outcomes in the 65 and older population.

\section{Implications of Effective Vaccines Against Respiratory Syncytial Virus}

\section{Respiratory Syncytial Virus Causes Serious Respiratorty Illness in Older Adults}

RSV is a commonly circulating virus during the winter months and accounts for $2-5 \%$ of pneumonias in community-dwelling older adults (reviewed in Falsey (2007)). The importance of this respiratory illness, particularly in older adults, is increasingly recognized; it was recently reported that RSV causes 10,000 excess deaths and is second only to the $\mathrm{A} / \mathrm{H} 3 \mathrm{~N} 2$ strains of influenza as a cause of death due to viral respiratory illness in the age 65 and older population (Thompson et al. 2003; Mullooly et al. 2007). Although the virus is genetically stable over time (in contrast to influenza), repeat infections throughout adult life are common suggesting the immunity to this virus wanes over time. Those older adults with increased risk for severe disease are those with congestive heart failure and chronic lung disease, the severely immunocompromised, and those living in long-term care facilities (Falsey et al. 1992). Estimates of RSV disease in this setting range from 5 to $10 \%$ of residents per year with pneumonia and death in $10-20 \%$ and $2-5 \%$ of cases, respectively. As with influenza illness in older adults, RSV results in prolonged 
lengths of hospital stay, significant disability and loss of independence in basic activities of daily living, and the need for a higher level of care at hospital discharge (Falsey et al. 2005). A recent analysis of RSV illness in the context of a large influenza vaccine trial showed that RSV causes a significant proportion of the moderate to severe influenza-like illness during the winter months (Falsey et al. 2014).

Studies of the immune response to RSV have shown that high levels of serum and/or nasal antibodies have been correlated with relative resistance to experimental challenge. Similarly, low serum and nasal antibody levels are risk factors for infection and disease severity in older adults but this is not an age-specific change (Walsh et al. 2004; Walsh and Falsey 2004). More importantly, older adults have a greater rise in antibody titers post infection than do their younger counterparts (Walsh and Falsey 2004). Since the RSV virus does not undergo antigenic drift over time, one would predict from this result, better protection against recurrent RSV illness would be predicted in older adults and is inconsistent with the relative increased risk of RSV infection with aging. A shift from Th1 to a Th2 response to RSV causes significant pathology in humans and in the aged mouse model, diminished CD8+ CTL responses associated with decreased IFN- $\gamma$ (Th1) and increased IL-4 (Th2), and higher RSV titers in lungs (Zhang et al. 2002). However, recent studies in human PBMC show no age-related changes in cytokine levels produced in response to RSV although the regulatory balance between inflammatory (IFN- $\gamma$ and anti-inflammatory (IL-10) cytokine levels may be altered (Looney et al. 2002).

\section{The Development of a Respiratory Syncytial Virus (RSV) Vaccine}

RSV circulates through much of the winter and often cocirculates with influenza during the mid-winter months. This presents a diagnostic challenge to clinicians as the symptoms of RSV illness completely overlap with those related to influenza illness (Wald et al. 1995). Thus, treatment approaches would be particularly problematic as a strategy for limiting the complications of RSV and none are currently available for use in adults. The development of a vaccine against RSV has proven to be a significant challenge, perhaps due to the reliability of antibody titers as a correlate protection in these trials. Recent efforts to develop an RSV vaccine for older adults have focused on combining RSV subunit proteins with adjuvants but these are in the early stages of development. The ongoing challenges to developing an RSV vaccine for older adults is that the correlates of protection are poorly understood, and the overlapping symptomatology and cocirculation with influenza over the winter months.

In summary, older adults experience significant complications of RSV illness but these complications are difficult to distinguish from the impact of influenza. Based on attack rates and impact of hospitalization in older adults, RSV is likely to cause significant disability in older adults. Immunologic correlates of clinical protection are not available and this presents a significant challenge to the development of the much needed vaccines against RSV for older adults. 


\section{Immune Senescence: Stimulating a Naïve Response}

\section{Pandemic Influenza Vaccines for Older Adults}

The threat of pandemic influenza has increased with the direct transmission of highly pathogenic avian $\mathrm{H} 5 \mathrm{~N} 1$ viruses to humans and many countries are in the process of or have completed plans to manage an anticipated influenza pandemic. While animals have transmitted H5N1 influenza to people in close contact with livestock, additional mutations or reassortment events will be required for widespread humanto-human transmission. Current research is focused on predicting the strains that are likely to evolve so that new influenza vaccines can be developed to protect against these new strains. The development of effective pandemic influenza vaccines is likely but continued reliance on killed virus or subunit vaccine technology will leave older adults at significantly higher risk of illness, disability, and death in the event of an influenza pandemic.

Targeting improvements in T-cell responses and thus protection against a number of strains will be particularly helpful for stimulating the senescent immune system against both seasonal and pandemic strains. In the case of H5N1, vaccines will not only have to stimulate an antibody response to the new vaccine strain but will also have to prime the T-cell response to influenza peptides derived from H5; age-related changes in naïve T-cells would result in decreased production of IL-2 and hence the proliferative response to the vaccine in both $\mathrm{B}$ and $\mathrm{T}$ cells. This has implications for both pre-pandemic and pandemic vaccines. Pre-pandemic vaccines if formulated to more potently stimulate T-cells could offer cross-protective immunity that would be enhanced with strain-specific antibodies against the pandemic strain. Although this strategy may offer enhanced protection in older adults, pre-pandemic and pandemic vaccines need to be tested for their ability to stimulate adequate antibody responses but also cross-protective cell-mediated immunity. In the absence of improvements in the current split-virus vaccine technology, an influenza pandemic could have a significant impact on older people with overwhelming consequences for the health care system.

\section{Other Viruses}

As individuals age, infectious diseases cause increasing morbidity and mortality. This is especially evident when older adults contract newly emerging diseases such as severe acute respiratory syndrome (SARS), which killed $50 \%$ of infected individuals over the age of 50 (Chen et al. 2005). The rapid human-to-human transmission of SARS exposed the entire age spectrum to a novel virus and highlighted the changes in the immune system that lead to increased morbidity and mortality rates with aging. Fortunately, the outbreak was controlled without a vaccine and before it could reach epidemic proportions. Older adults may also be naïve to viruses such as West Nile Virus (WNV) and Human Immunodeficiency Virus (HIV) and appear to be at increased risk of serious complications. When these viruses are contracted by 
an aged host, the senescent immune system may produce a less effective response compared to young adults. Evidence for this decline is from epidemiologic studies showing much higher mortality rates in older compared to young adults with WNV (Nash et al. 2001). However, a recent study has shown that there is no loss with aging in the polyfunctionality of CD8 $+\mathrm{T}$ cells responding to WNV infection (Lelic et al. 2012). It remains to be determined whether changes in Foxp3+CD4+ T cells may have a role in suppressing the CD8+ T cell response.

HIV prevalence is increasing and with aging of the population; HIV-infected patients aged 50 years and older now represent $10-13 \%$ of the HIV-infected population in the United States (Casau 2005). Both HIV and aging have been associated with the development of replicative senescence of T lymphocytes and increased risk of infection (Effros 2004). Replicative senescence results from chronic stimulation of the immune system and is associated with telomere shortening and loss of CD28 expression on CD8 T cells (van Baarle et al. 2005). These changes will need to be considered in the development of new therapies to improve the immune system and response to vaccination (Effros 2007). Recently, a population of memory T cells with a naïve phenotype has been identified and is a potential target for immunotherapy in the treatment of persistent infections such as HIV (Pulko et al. 2016).

\section{Immune Senescence: Vaccines Against Bacterial Pathogens}

\section{Pneumococcal Vaccination}

Streptococcus pneumoniae is an important cause of morbidity and mortality as a leading cause of community acquired infections including bacterial pneumonia, meningitis, and bacteremia. Amongst the highest risk groups and who bear the greatest burden of disease in the developed world are adults aged 65 years and older. Although the current 23-valent vaccine containing pneumococcal capsular polysaccharide (PPV23) is cost-effective in this population (Fedson 1992; Sisk et al. 1997), its efficacy may be limited by age-associated changes in the immune response to these vaccines. Although there is no age-related decline in the antibody response to pneumococcal vaccination when healthy young and older adults are compared, consistent antibody responses to all 23 serotypes contained in vaccine may not be achieved in older adults (Rubins et al. 1999). In addition, opsonophagocytic activity, the major effector mechanism for clearing pneumococcus appears to decline with aging (Kolibab et al. 2005). Further, there is a significant decline in antibody titers to PPS at 6 years following pneumococcal vaccination (Musher et al. 1993). Recommendations for PPV23 vaccination at age 65 are currently under review to include the new PCV13, which is a protein-conjugated vaccine containing nontoxic diphtheria toxin conjugated to 13 serotypes of pneumococcal polysaccharide.

A large randomized placebo-controlled trial of PCV conducted in The Netherlands in almost 85,000 adults $\geq 65$ years of age demonstrated an estimated $45.6 \%$ vaccine efficacy against both invasive (bacteremia) and noninvasive (pneumonia) pneumococcal disease for up to 4 years following vaccination (Bonten et al. 2015). 
This trial utilized a novel antigen detection assay of pneumococcal serotypes in the urine, in the diagnosis of both pneumococcal bacteremia and pneumonia. Prior to the development of this assay, vaccine efficacy and effectiveness studies have been limited the diagnosis of pneumococcal disease to the detection of pneumococcus in the sputum, blood, or cerebrospinal fluid, posing a significant challenge to studies in older adults. Studies have shown that the introduction of PCV7 into the childhood vaccination schedule has led to herd immunity in older adults whereby the circulation of these serotypes contained in the vaccine begin to decline and thus are not transmitted to older adults. Previous studies were based on the detection of invasive pneumococcal disease. More recent studies utilizing urinary antigen detection have shown that this protection applies to both invasive and noninvasive pneumococcal disease in older adults (van Werkhoven et al. 2016). These observations support the emerging policies for pneumococcal vaccination in older adults to include both PCV13 and PPV23 in the vaccination schedule.

PPV23 vaccine containing only purified pneumococcal polysaccharide stimulates antibody production through a T-independent type 2 (TI-2) response (one not requiring T-cell help and lacking memory) (Bruyn 1992). A Finnish study of older adults showed serotype-related differences in the serum antibody response to PPV23, suggesting that some serotypes are weak immunogens in older adults (Sankilampi et al. 1996) and these T-independent responses are more short-lived and may not be adequately boosted with revaccination. Protein-conjugated pneumococcal vaccines (PCV) were developed to facilitate T-cell cooperation (Perry and Catterall 1994) and thus may be more effective in targeting T cell responses that are known to decline with aging. Although fewer serotypes are represented in the current PCV13 vaccine, it appears to be more effective than PPV23, albeit for the serotypes contained in the vaccine as there is no known cross-reactivity in the antibody responses between the different serotype polysaccharides. In light of the enhanced efficacy of PCV13 and the anticipated increase in the circulation of non-PCV13 serotypes due to the PCV13 effects on herd immunity, pneumococcal vaccine schedules for older adults are being modified to include PCV13 followed by PPV23 to provide protection against the serotypes not contained in PCV13.

Cytokine responses to pneumococcal antigens have been shown to regulate responses to protein- and polysaccharide-specific antibody responses (Khan et al. 2004) and may be important in the pathogenesis of pneumococcal diseases (Kemp et al. 2002). Cytokine responses to the whole pneumococcus could explain changes in the virulence of different serotypes in older adults (Robinson et al. 2001) and in comparison to cytokine responses in younger adults (Arva and Andersson 1999). TNF- $\alpha$ produced by macrophages is associated with an initial inflammatory response to pneumococcal invasion (Perry and Catterall 1994; van der Poll et al. 1996) and has been found to be important in the development of antibodies to pneumococcal surface proteins (Khan et al. 2004; Khan et al. 2002). Increased levels of IL-10, an anti-inflammatory cytokine product of both macrophages and regulatory $\mathrm{T}$ cells, have been associated with increased risk for pneumococcal infection (van der Poll et al. 1996), but this cytokine becomes important for immunomodulation of the inflammatory response in the recovery from pneumococcal infection (Williams 
et al. 2015). Moreover, the gut microbiota has been shown in the mouse model to have role in the regulation of TNF- $\alpha$ and IL-10 in defense mechanisms against pneumococcal pneumonia (Schuijt et al. 2016) suggesting that the dysregulation of cytokine responses with aging may be more complicated than what can be ascribed to immune senescence alone.

\section{Immune Senescence: Altering Responses to Endogenous Proteins}

\section{Vaccines for Alzheimer's Disease}

Alzheimer's disease (AD) is caused by the deposition of $\beta$-amyloid protein $(A \beta)$ in the brain with toxic effects leading to neuronal cell death, amyloid plaque formation, and the development of neurofibrillary tangles. Based upon studies in mice, a vaccine containing the $A \beta_{1-42}$ peptide was shown to stimulate antibody production and improved cognitive function in mouse models of $\mathrm{AD}$. This vaccine was advanced to a Phase II clinical trial based on the demonstration of no significant adverse effects of vaccination in a Phase I trial that included 200 subjects. The Phase II trial was halted due to the development of aseptic meningoencephilitis in $6 \%$ of the 300 vaccinated subjects. Analysis of the antibody response to A $\beta$ showed a trend toward cognitive enhancement in the "responders" to vaccination (antibody titer to $\mathrm{A} \beta_{1-42} \geq 1: 2200$ ) but $22 \%$ of "responder" compared to $2 \%$ of "nonresponders" developed aseptic meningoencephilitis (Patton et al. 2006). These results suggested that adverse effects of the vaccine were related to the immune response to the vaccine rather than toxicity of the $A \beta_{1-42}$. Post-mortem studies of the meningoencephilitis cases showed substantial clearing of $A \beta$ from the brain but with marked T-cell infiltration in brain tissue.

The postulated age-related defect that leads to the pathology of $\mathrm{AD}$ related to APC uptake of $A \beta$ and stimulation of Th1 cytokines, an inflammatory response to $A \beta$. This defect is associated with inefficient phagocytosis of $A \beta$ and the production of inflammatory cytokines (IL-1 $\beta, \mathrm{TNF}-\alpha$ ) and chemokines, and nitric oxide leading to complement activation and T-cell apoptosis (Monsonego et al. 2003). The immune mechanism being targeted by the vaccine was T-cell-dependent antibody production against $A \beta$ to form $A \beta$-antibody complexes for more efficient clearing of the $A \beta$. Earlier studies had shown that $A \beta_{1-42}$ effectively stimulated a proliferative response in human peripheral blood mononuclear cells (PBMC). This response was increased in older compared to young adult subjects and a further significant increase was observed in older adult subjects with AD (Monsonego et al. 2003). It had been shown that $A \beta_{1-15}$ was responsible for $B$-cell stimulation and the production of antibodies to $A \beta$, and $A \beta_{15-42}$ most effectively stimulated T-cell proliferation and the production of both $T_{h} 1$ (IFN- $\gamma$ ) and $T_{h} 2$ (IL-13) cytokines. Because a $T_{h} 1\left(v s . T_{h} 2\right)$ response in the $\mathrm{AD}$ mouse model was associated with more effective clearance of $\mathrm{A} \beta$ in the mouse model, QS21 adjuvant was added to the A $\beta$ vaccine used in human trials to stimulate a Th1 response to the vaccine. It is postulated that the adjuvanted vaccine activated $A \beta$-specific memory $T$ cells that migrated to the sites of $A \beta$ 
deposition in the brain producing Th1 cytokines. Although the antibody response appeared to effectively clear $A \beta$, the inflammatory cytokine response of the T-cell infiltrate leads to meningoencephalitis. Since the $A \beta_{15-42}$ stimulated both Th1 and Th2 cytokines, it appears that the addition of the QS21 adjuvant may have been responsible for the serious adverse effects of the $A \beta$ vaccine (Monsonego and Weiner 2003). While efforts continue to develop immunologic-based therapies for $A D$, the results of this clinical trial continue to have significant consequences for future vaccine development and a recent review cites a critical need for new development strategies (Marciani 2016).

\section{Summary}

Age-related changes in the immune system have been associated with increased risk for infectious diseases. These are largely attributed age-related changes in T-cellmediated immunity and defects in defense mechanisms mediated by Th1 (IFN- $\gamma$ ) and CTL. This would suggest that more potent vaccines for older adults should stimulate Th1 and CTL to a particular pathogen. However, the underlying mechanism for defective immune responses in older people remains poorly understood including the potential negative impact of elevated levels of inflammatory cytokines (including IFN- $\gamma$ ) and the suppressive effects of regulatory T cells. This complex set of interactions in the activation of a protective immune response highlights the importance of developing correlates of protection and identifies novel targets for vaccine development to improve protection against a variety of infectious diseases in older adults. In spite of our limited understanding, a number of available vaccines have been shown to be cost-effective and even cost-saving in older adults. Future research to better understand the immunologic targets for the prevention or treatment of a variety of acute and chronic diseases and prevent disability in older adults will make a significant contribution to "adding life to years."

\section{References}

Ahmed AE, Nicholson KG, Nguyen-Van-Tam JS (1995) Reduction in mortality associated with influenza vaccine during 1989-90 epidemic. Lancet 346:591-595

Arva E, Andersson B (1999) Induction of phagocyte-stimulating and Th1-promoting cytokines by in vitro stimulation of human peripheral blood mononuclear cells with Streptococcus pneumoniae. Scand J Immunol 49:417-423

Arvin AM (2008) Humoral and cellular immunity to varicella-zoster virus: An overview. J Infect Dis 197(Suppl 2):S58-S60

Arvin AM, Moffat JF, Redman R (1996) Varicella-zoster virus: Aspects of pathogenesis and host response to natural infection and varicella vaccine. Adv Virus Res 46:263-309

Askonas BA, Mullbacher A, Ashman RB (1982) Cytotoxic T-memory cells in virus infection and the specificity of helper T cells. Immunology 45:79-84

Baiker A, Fabel K, Cozzio A et al (2004) Varicella-zoster virus infection of human neural cells in vivo. Proc Natl Acad Sci USA 101:10792-10797 
Behzad H, Huckriede A, Haynes L et al (2012) GLA-SE, a synthetic TLR4 agonist, enhances T cell responses to influenza vaccine in older adults. J Infect Dis 205:466-473

Belongia EA, Simpson MD, King JP et al (2016) Variable influenza vaccine effectiveness by subtype: A systematic review and meta-analysis of test-negative design studies. Lancet Infect Dis 16(8):942-951

Benoit A, Beran J, Devaster JM et al (2015) Hemagglutination inhibition antibody titers as a correlate of protection against seasonal A/H3N2 influenza disease. Open Forum Infect Dis 2:ofv067

Bleackley RC, Lobe CG, Duggan B et al (1988) The isolation and characterization of a family of serine protease genes expressed in activated cytotoxic T lymphocytes. Immunol Rev 103:5-19

Bonten MJ, Huijts SM, Bolkenbaas M et al (2015) Polysaccharide conjugate vaccine against pneumococcal pneumonia in adults. N Engl J Med 372:1114-1125

Boon AC, Fringuelli E, Graus YM et al (2002) Influenza A virus specific T cell immunity in humans during aging. Virology 299:100-108

Bright RA, Carter DM, Daniluk S et al (2007) Influenza virus-like particles elicit broader immune responses than whole virion inactivated influenza virus or recombinant hemagglutinin. Vaccine 25:3871-3878

Brisson M, Edmunds WJ, Law B et al (2001) Epidemiology of varicella zoster virus infection in Canada and the United Kingdom. Epidemiol Infect 127:305-314

Bruyn GA (1992) Pneumococcal immunisation and the healthy elderly. Lancet 340:1418

Butchko GM, Armstrong RB, Ennis FA (1978) Specificity studies on the proliferative response of thymus-derived lymphocytes to influenza viruses. J Immunol 121:2381-2385

Casau NC (2005) Perspective on HIV infection and aging: Emerging research on the horizon. Clin Infect Dis 41:855-863

Chen Q, Liang WN, Liu GF et al (2005) Case fatality rate of severe acute respiratory syndromes in Beijing. Biomed Environ Sci 18:220-226

Cohrs RJ, Gilden DH, Mahalingam R (2004) Varicella zoster virus latency, neurological disease and experimental models: An update. Front Biosci 9:751-762

Cunningham AL, Dworkin RH (2000) The management of post-herpetic neuralgia. BMJ 321:778-779

Cunningham AL, Lal H, Kovac M, et al (2016) Efficacy of the Herpes Zoster Subunit Vaccine in Adults 70 Years of Age or Older. N Engl J Med 375:1019-32

Darmon AJ, Nicholson DW, Bleackley RC (1995) Activation of the apoptotic protease CPP32 by cytotoxic T-cell-derived granzyme B. Nature 377:446-448

Demotz S, Grey HM, Sette A (1990) The minimal number of class II MHC-antigen complexes needed for T cell activation. Science 249:1028-1030

Derhovanessian E, Theeten H, Hahnel K, Van Damme P, Cools N, Pawelec G (2013) Cytomegalovirus-associated accumulation of late-differentiated CD4 T-cells correlates with poor humoral response to influenza vaccination. Vaccine 31:685-690

Derhovanessian E, Maier AB, Hahnel K, McElhaney JE, Slagboom EP, Pawelec G (2014) Latent infection with cytomegalovirus is associated with poor memory CD4 responses to influenza A core proteins in the elderly. J Immunol 193:3624-3631

DiazGranados CA, Dunning AJ, Kimmel M et al (2014) Efficacy of high-dose versus standard-dose influenza vaccine in older adults. N Engl J Med 371:635-645

Didierlaurent AM, Collignon C, Bourguignon P et al (2014) Enhancement of adaptive immunity by the human vaccine adjuvant AS01 depends on activated dendritic cells. J Immunol 193:1920-1930

Doherty PC, Topham DJ, Tripp RA, Cardin RD, Brooks JW, Stevenson PG (1997) Effector CD4+ and CD8+ T-cell mechanisms in the control of respiratory virus infections. Immunol Rev 159:105-117

Drolet M, Brisson M, Schmader KE et al (2010) The impact of herpes zoster and postherpetic neuralgia on health-related quality of life: A prospective study. CMAJ 182:1731-1736 
Effros RB (1997) Loss of CD28 expression on T lymphocytes: A marker of replicative senescence. Dev Comp Immunol 21:471-478

Effros RB (2003) Genetic alterations in the ageing immune system: Impact on infection and cancer. Mech Ageing Dev 124:71-77

Effros RB (2004) Replicative senescence of CD8 T cells: Effect on human ageing. Exp Gerontol 39:517-524

Effros RB (2007) Role of T lymphocyte replicative senescence in vaccine efficacy. Vaccine 25:599-604

Effros RB, Doherty PC, Gerhard W, Bennink J (1977) Generation of both cross-reactive and virusspecific T-cell populations after immunization with serologically distinct influenza A viruses. J Exp Med 145:557-568

Effros RB, Boucher N, Porter V et al (1994) Decline in CD28+ T cells in centenarians and in longterm $\mathrm{T}$ cell cultures: A possible cause for both in vivo and in vitro immunosenescence. Exp Gerontol 29:601-609

Effros RB, Dagarag M, Valenzuela HF (2003) In vitro senescence of immune cells. Exp Gerontol $38: 1243-1249$

Engwerda CR, Handwerger BS, Fox BS (1994) Aged T cells are hyporesponsive to costimulation mediated by CD28. J Immunol 152:3740-3747

Ennis FA, Rook AH, Qi YH et al (1981) HLA restricted virus-specific cytotoxic T-lymphocyte responses to live and inactivated influenza vaccines. Lancet 2:887-891

Ewen C, Kane KP, Shostak I et al (2003) A novel cytotoxicity assay to evaluate antigen-specific CTL responses using a colorimetric substrate for Granzyme B. J Immunol Methods 276:89-101

Falsey AR (2007) Respiratory syncytial virus infection in adults. Semin Respir Crit Care Med 28:171-181

Falsey AR, Treanor JJ, Betts RF, Walsh EE (1992) Viral respiratory infections in the institutionalized elderly: Clinical and epidemiologic findings. J Am Geriatr Soc 40:115-119

Falsey AR, Hennessey PA, Formica MA, Cox C, Walsh EE (2005) Respiratory syncytial virus infection in elderly and high-risk adults. N Engl J Med 352:1749-1759

Falsey AR, McElhaney JE, Beran J et al (2014) Respiratory syncytial virus and other respiratory viral infections in older adults with moderate to severe influenza-like illness. J Infect Dis 209:1873-1881

Feder HM Jr, Hoss DM (2004) Herpes zoster in otherwise healthy children. Pediatr Infect Dis J 23:451-457. quiz 8-60

Fedson DS (1992) Clinical practice and public policy for influenza and pneumococcal vaccination of the elderly. Clin Geriatr Med 8:183-199

Ferguson FG, Wikby A, Maxson P, Olsson J, Johansson B (1995) Immune parameters in a longitudinal study of a very old population of Swedish people: A comparison between survivors and non-survivors. J Gerontol A Biol Sci Med Sci 50:B378-BB82

Franceschi C, Monti D, Sansoni P, Cossarizza A (1995) The immunology of exceptional individuals: The lesson of centenarians. Immunol Today 16:12-16

Franceschi C, Capri M, Monti D et al (2007) Inflammaging and anti-inflammaging: A systemic perspective on aging and longevity emerged from studies in humans. Mech Ageing Dev 128:92-105

Frasca D, Blomberg BB (2014) B cell function and influenza vaccine responses in healthy aging and disease. Curr Opin Immunol 29:112-118

Gardner EM, Murasko DM (2002) Age-related changes in Type 1 and Type 2 cytokine production in humans. Biogerontology 3:271-290

Goodwin K, Viboud C, Simonsen L (2005) Antibody response to influenza vaccination in the elderly: A quantitative review. Vaccine 24(8):1159-1169

Goronzy JJ, Fulbright JW, Crowson CS, Poland GA, O'Fallon WM, Weyand CM (2001) Value of immunological markers in predicting responsiveness to influenza vaccination in elderly individuals. J Virol 75:12182-12187 
Gorse GJ, Belshe RB (1990) Enhancement of anti-influenza A virus cytotoxicity following influenza A virus vaccination in older, chronically ill adults. J Clin Microbiol 28:2539-2550

Gorse GJ, O'Connor TZ, Young SL et al (2003) Efficacy trial of live, cold-adapted and inactivated influenza virus vaccines in older adults with chronic obstructive pulmonary disease: A VA cooperative study. Vaccine 21:2133-2144

Govaert TM, Sprenger MJ, Dinant GJ, Aretz K, Masurel N, Knottnerus JA (1994) Immune response to influenza vaccination of elderly people. A randomized double-blind placebocontrolled trial. Vaccine 12:1185-1189

Gowrishankar K, Steain M, Cunningham AL et al (2010) Characterization of the host immune response in human Ganglia after herpes zoster. J Virol 84:8861-8870

Hackett CJ, Eisenlohr LC (1990) Virus entry and antigen biosynthesis in the processing and presentation of class-II MHC-restricted T-cell determinants of influenza virus. Immunol Res 9:103-114

Hackett CJ, Yewdell JW, Bennink JR, Wysocka M (1991) Class II MHC-restricted T cell determinants processed from either endosomes or the cytosol show similar requirements for host protein transport but different kinetics of presentation. J Immunol 146:2944-2951

Haynes L, Eaton SM, Burns EM, Rincon M, Swain SL (2004) Inflammatory cytokines overcome age-related defects in CD4 T cell responses in vivo. J Immunol 172(9):5194

Hope-Simpson RE (1965) The nature of herpes zoster: A long-term study and a new hypothesis. Proc R Soc Med 58:9-20

Hosaka Y, Sasao F, Yamanaka K, Bennink JR, Yewdell JW (1988) Recognition of noninfectious influenza virus by class I-restricted murine cytotoxic T lymphocytes. J Immunol 140:606-610

Huckriede A, Bungener L, Stegmann T et al (2005) The virosome concept for influenza vaccines. Vaccine 23(Suppl 1):S26-S38

Jenkins MR, Kedzierska K, Doherty PC, Turner SJ (2007) Heterogeneity of effector phenotype for acute phase and memory influenza A virus-specific CTL. J Immunol 179:64-70

Jenne DE, Tschopp J (1988) Granzymes, a family of serine proteases released from granules of cytolytic T lymphocytes upon T cell receptor stimulation. Immunol Rev 103:53-71

Johnson BJ, Costelloe EO, Fitzpatrick DR et al (2003) Single-cell perforin and granzyme expression reveals the anatomical localization of effector CD8+ T cells in influenza virus-infected mice. Proc Natl Acad Sci USA 100:2657-2662. Epub 003 Feb 24

Kang I, Hong MS, Nolasco $\mathrm{H}$ et al (2004) Age-associated change in the frequency of memory CD4 + T cells impairs long term CD4+ T cell responses to influenza vaccine. J Immunol 173:673-681

Keitel WA, Cate TR, Couch RB (1988) Efficacy of sequential annual vaccination with inactivated influenza virus vaccine. Am J Epidemiol 127:353-364

Kemp K, Bruunsgaard H, Skinhoj P, Klarlund Pedersen B (2002) Pneumococcal infections in humans are associated with increased apoptosis and trafficking of type 1 cytokine-producing T cells. Infect Immun 70:5019-5025

Khan AQ, Shen Y, ZQ W, Wynn TA, Snapper CM (2002) Endogenous pro- and anti-inflammatory cytokines differentially regulate an in vivo humoral response to Streptococcus pneumoniae. Infect Immun 70:749-761

Khan AQ, Lees A, Snapper CM (2004) Differential regulation of IgG anti-capsular polysaccharide and antiprotein responses to intact Streptococcus pneumoniae in the presence of cognate CD4+ T cell help. J Immunol 172:532-539

Kolibab K, Smithson SL, Shriner AK et al (2005) Immune response to pneumococcal polysaccharides 4 and 14 in elderly and young adults. I. Antibody concentrations, avidity and functional activity. Immun Ageing 2:10

Kucharski AJ, Lessler J, Read JM et al (2015) Estimating the life course of influenza A(H3N2) antibody responses from cross-sectional data. PLoS Biol 13:e1002082

Lamb CA, Yewdell JW, Bennink JR, Cresswell P (1991) Invariant chain targets HLA class II molecules to acidic endosomes containing internalized influenza virus. Proc Natl Acad Sci USA 88:5998-6002 
Lawrence CW, Ream RM, Braciale TJ (2005) Frequency, specificity, and sites of expansion of CD8+ T cells during primary pulmonary influenza virus infection. J Immunol 174:5332-5340

Lelic A, Verschoor CP, Ventresca M et al (2012) The polyfunctionality of human memory CD8+ $\mathrm{T}$ cells elicited by acute and chronic virus infections is not influenced by age. PLoS Pathog 8:e1003076

Levin MJ, Smith JG, Kaufhold RM et al (2003) Decline in varicella-zoster virus (VZV)-specific cell-mediated immunity with increasing age and boosting with a high-hose VZV vaccine. J Infect Dis 188:1336-1344. Epub 2003 Oct 17

Looney RJ, Falsey AR, Walsh E, Campbell D (2002) Effect of aging on cytokine production in response to respiratory syncytial virus infection. J Infect Dis 185(5):682

Marciani DJ (2016) A retrospective analysis of the Alzheimer's disease vaccine progress - The critical need for new development strategies. J Neurochem 137:687-700

Mbawuike IN, Lange AR, Couch RB (1993) Diminished influenza A virus-specific MHC class I-restricted cytotoxic T lymphocyte activity among elderly persons. Viral Immunol 6:55-64

McElhaney JE (2005) The unmet need in the elderly: Designing new influenza vaccines for older adults. Vaccine 23(Suppl 1):S10-S25

McElhaney JE, Xie D, Hager WD et al (2006) T cell responses are better correlates of vaccine protection in the elderly. J Immunol 176:6333-6339

McElhaney JE, Ewen C, Zhou X et al (2009) Granzyme B: Correlates with protection and enhanced CTL response to influenza vaccination in older adults. Vaccine 27:2418-2425

McElhaney JE, Beran J, Devaster JM et al (2013) AS03-adjuvanted versus non-adjuvanted inactivated trivalent influenza vaccine against seasonal influenza in elderly people: A phase 3 randomised trial. Lancet Infect Dis 13:485-496

McElhaney JE, Kuchel GA, Zhou X, Swain SL, Haynes L (2016) T-cell immunity to influenza in older adults: A pathophysiological framework for development of more effective vaccines. Front Immunol 7:41

McLean HQ, Thompson MG, Sundaram ME et al (2014) Impact of repeated vaccination on vaccine effectiveness against influenza $\mathrm{A}(\mathrm{H} 3 \mathrm{~N} 2)$ and B during 8 seasons. Clin Infect Dis 59:1375-1385

McMichael AJ, Gotch FM, Noble GR, Beare PA (1983a) Cytotoxic T-cell immunity to influenza. N Engl J Med 309:13-17

McMichael AJ, Gotch FM, Dongworth DW, Clark A, Potter CW (1983b) Declining T-cell immunity to influenza, 1977-82. Lancet 2:762-764

Mitchell DM, Callard RE (1983) Fine specificity of the in vitro antibody response to influenza virus by human blood lymphocytes. J Immunol 131:1229-1233

Monsonego A, Weiner HL (2003) Immunotherapeutic approaches to Alzheimer's disease. Science 302:834-838

Monsonego A, Zota V, Karni A et al (2003) Increased T cell reactivity to amyloid beta protein in older humans and patients with Alzheimer disease. J Clin Invest 112:415-422

Mosterin Hopping A, McElhaney J, Fonville JM, Powers DC, Beyer WE, Smith DJ (2016) The confounded effects of age and exposure history in response to influenza vaccination. Vaccine 34:540-546

Mullooly JP, Bridges CB, Thompson WW et al (2007) Influenza- and RSV-associated hospitalizations among adults. Vaccine 25:846-855

Murasko DM, Bernstein ED, Gardner EM et al (2002) Role of humoral and cell-mediated immunity in protection from influenza disease after immunization of healthy elderly. Exp Gerontol 37:427-439

Musher DM, Groover JE, Rowland JM et al (1993) Antibody to capsular polysaccharides of Streptococcus pneumoniae: Prevalence, persistence, and response to revaccination. Clin Infect Dis 17:66-73

Nash D, Mostashari F, Fine A et al (2001) The outbreak of West Nile virus infection in the New York City area in 1999. N Engl J Med 344:1807-1814 
Nguyen HH, Moldoveanu Z, Novak MJ et al (1999) Heterosubtypic immunity to lethal influenza A virus infection is associated with virus-specific CD8(+) cytotoxic T lymphocyte responses induced in mucosa-associated tissues. Virology 254:50-60

Nichol KL, Margolis KL, Wuorenma J, Von Sternberg T (1994) The efficacy and cost effectiveness of vaccination against influenza among elderly persons living in the community. N Engl J Med 331:778-784

Ouyang Q, Wagner WM, Wikby A et al (2003) Large numbers of dysfunctional CD8+ T lymphocytes bearing receptors for a single dominant CMV epitope in the very old. J Clin Immunol 23:247-257

Oxman MN, Levin MJ (2008) Vaccination against Herpes Zoster and Postherpetic Neuralgia. J Infect Dis 197(Suppl 2):S228-S236

Oxman MN, Levin MJ, Johnson GR et al (2005) A vaccine to prevent herpes zoster and postherpetic neuralgia in older adults. N Engl J Med 352:2271-2284

Pasternack MS, Eisen HN (1985) A novel serine esterase expressed by cytotoxic T lymphocytes. Nature 314:743-745

Patton RL, Kalback WM, Esh CL et al (2006) Amyloid-beta peptide remnants in AN-1792immunized Alzheimer's disease patients: A biochemical analysis. Am J Pathol 169:1048-1063

Pawelec G, Akbar A, Caruso C, Solana R, Grubeck-Loebenstein B, Wikby A (2005) Human immunosenescence: Is it infectious? Immunol Rev 205:257-268

Perry FE, Catterall JR (1994) The pneumococcus: Host-organism interactions and their implications for immunotherapy and immunoprophylaxis. Thorax 49:946-950

Plowden J, Renshaw-Hoelscher M, Engleman C, Katz J, Sambhara S (2004) Innate immunity in aging: Impact on macrophage function. Aging Cell 3:161-167

Powers DC (1993) Influenza A virus-specific cytotoxic T lymphocyte activity declines with advancing age [see comments]. J Am Geriatr Soc 41:1-5

Puig-Barbera J, Diez-Domingo J, Perez Hoyos S, Belenguer Varea A, Gonzalez Vidal D (2004) Effectiveness of the MF59-adjuvanted influenza vaccine in preventing emergency admissions for pneumonia in the elderly over 64 years of age. Vaccine 23:283-289

Pulko V, Davies JS, Martinez C et al (2016) Human memory T cells with a naive phenotype accumulate with aging and respond to persistent viruses. Nat Immunol 17(8):966-975

Ray SJ, Franki SN, Pierce RH et al (2004) The collagen binding alphalbetal integrin VLA-1 regulates CD8 $\mathrm{T}$ cell-mediated immune protection against heterologous influenza infection. Immunity 20:167-179

Reber AJ, Kim JH, Biber R et al (2015) Preexisting immunity, more than aging, influences influenza vaccine responses. Open Forum Infect Dis 2:ofv052

Robinson KA, Baughman W, Rothrock G et al (2001) Epidemiology of invasive Streptococcus pneumoniae infections in the United States, 1995-1998: Opportunities for prevention in the conjugate vaccine era. JAMA 285:1729-1735

Rubins JB, Alter M, Loch J, Janoff EN (1999) Determination of antibody responses of elderly adults to all 23 capsular polysaccharides after pneumococcal vaccination. Infect Immun 67:5979-5984

Russell SM, Liew FY (1979) T cells primed by influenza virion internal components can cooperate in the antibody response to haemagglutinin. Nature 280:147-148

Sankilampi U, Honkanen PO, Bloigu A, Herva E, Leinonen M (1996) Antibody response to pneumococcal capsular polysaccharide vaccine in the elderly. J Infect Dis 173:387-393

Saurwein-Teissl M, Lung TL, Marx F et al (2002) Lack of antibody production following immunization in old age: Association with $\mathrm{CD} 8(+) \mathrm{CD} 28(-) \mathrm{T}$ cell clonal expansions and an imbalance in the production of Th1 and Th2 cytokines. J Immunol 168:5893-5899

Schmader K (2001) Herpes zoster in older adults. Clin Infect Dis 32:1481-1486. Epub 2001 Apr 17

Schuijt TJ, Lankelma JM, Scicluna BP et al (2016) The gut microbiota plays a protective role in the host defence against pneumococcal pneumonia. Gut 65:575-583

Sei JJ, Cox KS, Dubey SA, et al (2015) Effector and Central Memory Poly-Functional CD4(+) and CD8(+) T Cells are Boosted upon ZOSTAVAX((R)) Vaccination. Front Immunol 6:553 
Shahid Z, Kleppinger A, Gentleman B, Falsey AR, McElhaney JE (2010) Clinical and immunologic predictors of influenza illness among vaccinated older adults. Vaccine 28:6145-6151

Sisk JE, Moskowitz AJ, Whang W et al (1997) Cost-effectiveness of vaccination against pneumococcal bacteremia among elderly people. JAMA 278:1333-1339

Skowronski DM, Tweed SA, De Serres G (2008) Rapid decline of influenza vaccine-induced antibody in the elderly: Is it real, or is it relevant? J Infect Dis 197:490-502

Skowronski DM, Hottes TS, McElhaney JE et al (2011) Immuno-epidemiologic correlates of pandemic H1N1 surveillance observations: Higher antibody and lower cell-mediated immune responses with advanced age. J Infect Dis 203:158-167

Smith JG, Levin M, Vessey R et al (2003) Measurement of cell-mediated immunity with a VaricellaZoster Virus-specific interferon-gamma ELISPOT assay: Responses in an elderly population receiving a booster immunization. J Med Virol 70(Suppl 1):S38-S41

Sridhar S, Begom S, Bermingham A et al (2013) Cellular immune correlates of protection against symptomatic pandemic influenza. Nat Med 19:1305-1312

Steain M, Sutherland JP, Rodriguez M, Cunningham AL, Slobedman B, Abendroth A (2014) Analysis of $\mathrm{T}$ cell responses during active varicella-zoster virus reactivation in human ganglia. J Virol 88:2704-2716

Thomas SL, Hall AJ (2004) What does epidemiology tell us about risk factors for herpes zoster? Lancet Infect Dis 4:26-33

Thompson WW, Shay DK, Weintraub E et al (2003) Mortality associated with influenza and respiratory syncytial virus in the United States. JAMA 289:179-186

Thompson WW, Shay DK, Weintraub E et al (2004) Influenza-associated hospitalizations in the United States. JAMA 292:1333-1340

van Baarle D, Tsegaye A, Miedema F, Akbar A (2005) Significance of senescence for virus-specific memory $\mathrm{T}$ cell responses: Rapid ageing during chronic stimulation of the immune system. Immunol Lett 97:19-29

van der Poll T, Marchant A, Keogh CV, Goldman M, Lowry SF (1996) Interleukin-10 impairs host defense in murine pneumococcal pneumonia. J Infect Dis 174:994-1000

van Werkhoven CH, Hollingsworth RC, Huijts SM et al (2016) Pneumococcal conjugate vaccine herd effects on non-invasive pneumococcal pneumonia in elderly. Vaccine 34:3275-3282

Vasto S, Colonna-Romano G, Larbi A, Wikby A, Caruso C, Pawelec G (2007) Role of persistent CMV infection in configuring T cell immunity in the elderly. Immun Ageing 4:2

Vescovini R, Biasini C, Fagnoni FF et al (2007) Massive load of functional effector CD4+ and CD8 $+\mathrm{T}$ cells against cytomegalovirus in very old subjects. J Immunol 179:4283-4291

Virelizier JL, Postlethwaite R, Schild GC, Allison AC (1974) Antibody responses to antigenic determinants of influenza virus hemagglutinin. I. Thymus dependence of antibody formation and thymus independence of immunological memory. J Exp Med 140:1559-1570

Voordouw AC, Sturkenboom MC, Dieleman JP et al (2004) Annual revaccination against influenza and mortality risk in community-dwelling elderly persons. JAMA 292:2089-2095

Vu T, Farish S, Jenkins M, Kelly H (2002) A meta-analysis of effectiveness of influenza vaccine in persons aged 65 years and over living in the community. Vaccine 20:1831-1836

Vukmanovic-Stejic M, Sandhu D, Sobande TO et al (2013) Varicella zoster-specific CD4+Foxp3+ $\mathrm{T}$ cells accumulate after cutaneous antigen challenge in humans. J Immunol 190:977-986

Vukmanovic-Stejic M, Sandhu D, Seidel JA et al (2015) The characterization of varicella zoster virus-specific T cells in skin and blood during aging. J Invest Dermatol 135:1752-1762

Wald TG, Miller BA, Shult P, Drinka P, Langer L, Gravenstein S (1995) Can respiratory syncytial virus and influenza $A$ be distinguished clinically in institutionalized older persons? J Am Geriatr Soc 43:170-174

Walsh EE, Falsey AR (2004) Age related differences in humoral immune response to respiratory syncytial virus infection in adults. J Med Virol 73:295-299

Walsh EE, Peterson DR, Falsey AR (2004) Risk factors for severe respiratory syncytial virus infection in elderly persons. J Infect Dis 189:233-238 
Weinert LA, Depledge DP, Kundu S et al (2015) Rates of vaccine evolution show strong effects of latency: Implications for varicella zoster virus epidemiology. Mol Biol Evol 32:1020-1028

Wikby A, Nilsson BO, Forsey R et al (2006) The immune risk phenotype is associated with IL-6 in the terminal decline stage: Findings from the Swedish NONA immune longitudinal study of very late life functioning. Mech Ageing Dev 127:695-704

Wilkinson TM, Li CK, Chui CS et al (2012) Preexisting influenza-specific CD4+ T cells correlate with disease protection against influenza challenge in humans. Nat Med 18:274-280

Williams AE, Jose RJ, Brown JS, Chambers RC (2015) Enhanced inflammation in aged mice following infection with Streptococcus pneumoniae is associated with decreased IL-10 and augmented chemokine production. Am J Physiol Lung Cell Mol Physiol 308:L539-L549

Xie D, McElhaney JE (2007) Lower GrB+ CD62Lhigh CD8 TCM effector lymphocyte response to influenza virus in older adults is associated with increased CD28null CD8 T lymphocytes. Mech Ageing Dev 128:392-400

Zhang Y, Wang Y, Gilmore X, Xu K, Wyde PR, Mbawuike IN (2002) An aged mouse model for RSV infection and diminished CD8(+) CTL responses. Exp Biol Med (Maywood) 227:133-140

Zhou X, Hopkins JW, Wang C et al (2016) IL-2 and IL-6 cooperate to enhance the generation of influenza-specific CD8 T cells responding to live influenza virus in aged mice and humans. Oncotarget 7(26):39171-39183 